\title{
Produção de Subjetividade: A Lição de O HOMEM Que Copiava
}

(Subjectivity Production: the Lesson of O Homem Que Copiava)

\author{
Décio RochA ${ }^{1}$ \\ (Universidade do Estado do Rio de Janeiro)
}

ABSTRACT: On the basis of a theoretical framework which will enable us to reflect on Modernity and assuming a discursive perspective in language studies, the purpose of this paper is to explore the productivity of the concept of subjectivity as defined by Deleuze, Guattari and other authors who distinguish subjectivity production and particular forms of subject as different modes of existence. In order to achieve our goal, we focus on the analysis of Jorge Furtado's film O homem que copiava. Results show some evidence that the discussion may be relevant to Discourse Analysis in what concerns the notions of production conditions, textual loops and discursive practice.

KEY-WORDS: subjectivity; alterity; production conditions of discourse; cinema.

RESUMO: Tomando por base um quadro teórico que nos ajuda a pensar a Modernidade e assentados numa perspectiva discursiva visando ao tratamento das práticas linguageiras, o objetivo do presente artigo é explorar a produtividade do conceito de subjetividade segundo Deleuze, Guattari e outros autores que distinguem, por um lado, a produção de subjetividade e, por outro, formas-sujeito particulares que se atualizam como diferentes modos de existência. Para alcançar nosso objetivo, centramos nossa atenção na análise do filme de Jorge Furtado, intitulado O homem que copiava. Os resultados encontrados são relevantes no campo da Análise do Discurso no que concerne ao debate relativo às noçôes de condições de produção, enlaçamentos e prática discursiva.

PALAVRAS-CHAVE: subjetividade; alteridade; condições de produção do discurso; cinema.

Professor Adjunto do Instituto de Aplicação e do Instituto de Letras da Universidade do Estado do Rio de Janeiro (UERJ), doutor em Lingüística Aplicada pela PUC-SP; bolsista CNPq.

D.E.L.T.A., 23:1, 2007 (97-126) 


\section{Introdução}

Um dos grandes desafios da contemporaneidade parece residir em um certo exercício de desnaturalização daquilo que se configurou como sujeito da Modernidade. Afinal, todos parecem acreditar na realidade daquilo que no curso dos últimos séculos se constituiu como sendo "o indivíduo", na obviedade de suas "paixões mais secretas", em seu "interior insondável"; muitos parecem, enfim, persuadidos de que negligenciar as demandas desse plano tão "íntimo" significa trair uma pretensa "condição humana". Com efeito, esquece-se na maioria das vezes que tal individualidade, tal "profundidade", é algo de produzido, algo datado, em consonância com o cumprimento de um determinado "projeto de humanidade". De acordo com uma tal vulgata, subjetividade expressão do subjetivo, intimismo, se equivalem. O que fazer a esse respeito? Como descolar a multiplicidade dos processos de subjetivação e a produção deste modo de subjetividade específico que se atualiza na forma-indivíduo?

A relevância do tema que ora proponho abordar pode ser justificada se for lembrado que trabalhar com práticas de linguagem pressupõe de forma incontornável uma explicitação do modo como nos posicionamos a respeito do tema. A posição que assumo a esse respeito é ratificar a pertinência do debate que distingue, de um lado, uma certa forma-sujeito historicamente situada e, de outro, a multiplicidade dos processos de subjetivação. Tal distância parece colocar em cena uma dupla problemática:

- a articulação entre formas instituídas e forças instituintes;

- o sistemático apagamento da história, o qual é responsável por fazer das formas instituídas um sempre-lá;

Penso que o debate apenas anunciado repercutirá de forma decisiva no curso dos estudos voltados para as práticas linguageiras, tendo em vista a perspectiva inaugurada pela ênfase nos processos de subjetivação. Assim, diria que o problema a ser explorado neste texto é o da subjetividade e do tipo de relações que podemos estabelecer entre produção textual e seu entorno. Isto tem sido uma demanda no campo das ciências sociais, como já o atestam as iniciativas em Análise do Discurso dos anos 60 do último século. Dito de forma simples: como conceber o sujeito? como ler um texto? como articular sujeito / texto / entorno? 
Falar a respeito do caminho que desejo percorrer para pensar sobre o que move o homem na produção de diferentes modos de subjetivação significa oferecer alguns pontos de apoio para o leitor do presente artigo. Assim, inicio esta discussão pela apresentação do modo pelo qual se desqualifica o sujeito da razão para pensar o sujeito em $O$ homem que copiava. A seguir, no item 2, explicito que, se o homem da razão não pode corresponder ao que se persegue como modo de produção de subjetividade ${ }^{2}$, tampouco encontraremos a resposta que buscamos nos modelos inaugurados por Marx e Freud, por intermédio de uma certa concepção de ideológico e de inconsciente que se tornou hegemônica a partir dos trabalhos de Althusser, em sua releitura de Marx, e de Lacan, em relação a Freud. Por que razão o recurso a Marx e a Freud se mostra insuficiente? Porque falar de um sujeito duplamente determinado, pelo ideológico e pelo inconsciente, significa conferir lugar de destaque a formas de descentramento que parecem ainda apontar para o resgate de formas essencializadas (o homem não alienado, que poderia alcançar uma espécie de "maioridade social" resistindo às ideologias dominantes; o homem que supera os entraves de um inconsciente visto como da ordem do individual, etc.). Tais leituras voltadas para o ideológico e o inconsciente pretendem expulsar o sujeito cartesiano, mas os resultados obtidos não são suficientes para tal fim³ ${ }^{3}$.

A recusa do assujeitamento pelo ideológico e pelo inconsciente freudiano não implica, contudo, preconizar qualquer modelo de libertação para o sujeito. É disso que trataremos no terceiro item, quando traremos a concepção de produção de subjetividade que defendemos e um outro modo de conceber o inconsciente: o inconsciente maquínico de Deleuze e Guattari.

No quarto item, como o próprio título já o indica, passamos a um exercício de análise de $O$ homem que copiava, recuperando de que forma se atualiza no filme um determinado modo de subjetivação, ou, mais precisamente, como nele se atualiza o modo de subjetivação que defendemos no item anterior.

Em "Ultrapassar o modelo representacional macro do marxismo e do freudismo", quinto item deste trabalho, são trazidos à discussão dois con-

Sobre a noção de produção de subjetividade nos discursos midiáticos, ver Rocha (2005).

3 Quanto às insuficiências do modelo freudiano de inconsciente, remeto o leitor a Naffah Neto (1991). 
ceitos fundamentais para a afirmação de um novo conceito de subjetividade: o conceito deleuziano de dobra e a noção foucaultiana de acontecimentalização. Por esses recursos esperamos conseguir demonstrar por que razão um modelo baseado no ideológico e no inconsciente visto como lugar de representações não pode dar conta da produção de subjetividade.

No sexto item, faremos uma reflexão voltada para as implicações de todos esses debates com a investigação das práticas linguageiras. Nosso objetivo será o de avançar na compreensão de como o sujeito (e os textos) se articulam com seu entorno: velha questão dos encontros entre texto e contexto, recolocando em cena, sob uma outra ótica, o problema das "condições de produção". Finalmente, à guisa de conclusão, reafirma-se o sentido de alteridade possibilitado pelo modo como pensamos a produção de subjetividade, sendo reiterado, pelo recurso à noção de resistência, o caráter falacioso da oposição entre liberdade e assujeitamento.

\section{O Homem que Copiava: Desqualificação do Sujeito da Razão}

Eis o verdadeiro motor deste texto: o filme $O$ homem que copiava, de Jorge Furtado. Com efeito, a escritura deste artigo foi deflagrada pelo interesse que o filme é capaz de produzir como momento de reflexão acerca da problemática da subjetividade. Inicio pela apresentação da sinopse do filme ${ }^{4}$ :

André (Lázaro Ramos) é um jovem de 20 anos que trabalha na fotocopiadora da papelaria Gomide, localizada em Porto Alegre. André mora com a mãe e tem uma vida comum, basicamente vivendo de casa para o trabalho e realizando sempre as mesmas atividades. Num dia André se apaixona por Sílvia (Leandra Leal), uma vizinha, a qual passa a observar com os binóculos em seu quarto. Decidido a conhecê-la melhor, André descobre que ela trabalha em uma loja de roupas e, para conseguir uma aproximação, tenta de todas as formas conseguir 38 reais para comprar um suposto presente para sua mãe.

Se dissemos que $O$ bomem que copiava representa um momento singular de reflexão a respeito da problemática da subjetividade, isto se deve em primeiro lugar ao trabalho de desconstrução de um certo modelo de sujei-

A fonte em que localizamos a sinopse do filme encontra-se nas referências bibliográficas. 
to a que se procede desde o início do filme: a desconstrução do sujeito cartesiano da razão.

A desqualificação a que me refiro pode ser sustentada por um retorno a Foucault: é contra a concepção de um sujeito desde sempre aí, de um sujeito que preexistiria ao mundo social, político, cultural e econômico que o filme nos coloca; contra essa concepção própria da Modernidade que procura apreender o sujeito como uma propriedade da condição humana, forma de transcendência que se busca captar.

O sujeito da Modernidade que se apreende no "eu pensante" cartesiano pode, com efeito, assumir vários rostos, mas estará sempre localizado numa mesma filosofia da consciência. É o homem do dualismo entre mente e matéria, oposição bastante oportuna por garantir que se localize justamente na mente o que foi tomado como "sujeito individual", "sujeito centrado", capaz de exercer a razão, sempre idêntico a si mesmo. A esse conjunto de fatores que permitiu exorcizar as forças da alteridade denominou-se "identidade", garantia da permanência de um sujeito unificado.

Não é difícil sustentar a tese da absoluta aversão de $O$ homem que copiava por tal modelo de subjetividade, o que pode ser argumentado por vários ângulos. No caso deste trabalho, privilegiarei a explicitação da dimensão fragmentada da narrativa (e, por extensão, da caracterização dos personagens), a colagem que singulariza um dado exercício das práticas linguageiras no universo em tela. Com efeito, o espaço do filme é construído como um mosaico, isto é, colagem e superposição de cenas, de linguagens, etc., conduzindo-nos a algo que se poderia considerar como sendo uma certa "dimensão caótica" do filmes:

ANDRÉ: Eu moro em Porto Alegre, uma cidade no sul do Brasil. Moro no Quarto Distrito, na Presidente Roosevelt, que é essa rua.

Gravuras do Presidente Roosevelt e de sua mulher, num trabalho escolar, na fotocopiadora.

\footnotetext{
O texto dos diálogos que reproduzo constam no roteiro do filme, cuja fonte se encontra explicitada nas referências bibliográficas. Quanto à técnica de colagem, eis o que declara o próprio Jorge Furtado em depoimento para o Correio brasiliense (Fonte: verdesmares.globo.com, acesso em 04/08/ 05): "A idéia principal do filme veio do personagem André. Como ele tem uma visão fragmentada do mundo, pensei em transformar tudo em uma grande colagem. Um filme que muda várias vezes de gênero e até de ponto de vista".
} 
ANDRÉ: Roosevelt foi presidente dos Estados Unidos, era casado com uma gordinha que era prima dele. Ele ficou conhecido por causa da Doutrina Roosevelt, que não deu tempo de eu ler o que era.

Desenho de André: uma velha parecida com Eleanor Roosevelt.

ANDRÉ: Nem sei direito o que é doutrina, acho que é um monte de regras. Parece nome de uma velha. Vó Doutrina.

Eis como se produz no roteiro de $O$ homem que copiava a transição da mera informação referente ao nome da rua de Porto Alegre em que mora o personagem a algo de absolutamente outro: a criação de "Vó Doutrina", personagem dos quadrinhos produzidos por André que possui o rosto de Eleanor Roosevelt. A referida transição pode ser esquematizada da seguinte maneira: o nome da rua em que mora o personagem, Presidente Roosevelt, é associado a imagens do referido presidente vistas pelo protagonista em trabalhos escolares que ele fotocopia, prática profissional que lhe possibilita visualizar o rosto de Eleanor Roosevelt, esposa de Roosevelt, e saber que algo se consagrou na história como sendo a "doutrina Roosevelt". Ainda como deslocamentos sucessivos, acrescente-se o desconhecimento de André acerca do significado da palavra doutrina ("parece nome de velha"); finalmente, o "batismo" do personagem dos quadrinhos: uma velha senhora chamada "Vó Doutrina", produzida por intermédio da associação de um corpo desenhado por André com o rosto de Eleanor Roosevelt.

Exemplos como o indicado são a regra em $O$ homem que copiava, e não a exceção. Senão, vejamos: a colagem já está presente em todas as paredes do quarto de André, onde figuram recortes de toda a espécie; o espectador tem acesso a estilhaços do quarto de Sílvia, o qual é visto (ou adivinhado?) por André por meio de um binóculo: a tela aparece multifacetada em diferentes tomadas de faixas do quarto que procuram reconstruir uma gestalt apenas totalizada quando Sílvia instala a cortina japonesa - de grande transparência - que André lhe dá de presente.

É a mesma "bricolagem inventiva e fragmentada" com base na diversidade dos textos trazidos pelos clientes para fotocópia que marca a produção de saberes em André:

ANDRÉ: Às vezes dá para ler alguma revista na loja, mas a maior parte do tempo eu fico lendo as coisas que as pessoas trazem para copiar. Enquanto eu tou tirando as cópias, só consigo ler algumas linhas de cada folha. Já é alguma coisa. 
Em meio a tal diversidade de fragmentos que se acumulam na fotocopiadora, fragmentos constitutivos do saber do personagem, destaco:

- a presença de diferentes obras: livro de poemas de Shakespeare; $O$ impulso duplicador ${ }^{6}$; A vida - modo de usar, de Georges Perec;

- a fotocópia de imagens de natureza variada: uma cama com dossel, imagens da cultura inca e asteca, trabalho escolar de química, etc.;

- a sucessão de temas diversificados (e desconectados): síndrome do pânico, origem do dinheiro na China, o significado de viking em dinamarquês, etc.

A interferência de séries é, com efeito, o que parece reger a construção da narrativa e do perfil dos personagens. Trata-se sempre de saberes de diversas ordens que se sucedem sobre a fotocopiadora de André. Lógica do acaso, segundo a qual é sempre imprevisível que material será trazido para reprodução pelo próximo cliente. Tal lógica das associações fortuitas é o que se percebe em inúmeros outros momentos do filme:

- coincidências biográficas de Shakespeare e Cervantes (ambos morrem em 23 de abril de 1616);

- Santa Cecília, nome do prédio em que habita Sílvia, personagem por quem André se apaixona, e também nome daquela que foi mártir dos romanos;

- aquisição de uma nova copiadora a cores por Gomide, patrão de André, como acaso facilitador da entrada do personagem no mundo da contravenção (falsificação de cédulas bancárias);

- prêmio da loteria ganho por André (com a "incrível seqüência" de números vitoriosa - 1, 2, 3, 4, 5, 6), decorrente da estratégia utilizada pelo personagem de fazer apostas apenas para passar adiante as notas falsas.

A relação de séries em superposição poderia continuar de forma aparentemente ininterrupta. Fragmentos, estilhaços de vida presente e passa-

\footnotetext{
6 "O impulso duplicador" não é exatamente um livro, mas o título de um capítulo de Os descobridores, obra de Daniel Boorstin, de 1987.
} 
da, de várias linguagens que se recompõem num futuro imprevisível feito de recortes, de acasos.

Não é apenas o plano dos "conteúdos" que se submete a tal lógica da colagem. O tempo também é produzido numa lógica que se afasta do plano cronológico: ao tempo da história atual vem se sobrepor o tempo da imaginação do personagem. Eis o que ocorre na cena em que André se reporta a um tempo passado, quando era empacotador em um supermercado, sendo interpelado por uma cliente insatisfeita enquanto ele sonhava com a fama do grande jogador de futebol que havia se tornado, fazendo um gol bem ao estilo de Pelé:

\section{CENA 37 - SUPERMERCADO - INTERIOR/DIA}

André empacota compras num supermercado, o mesmo da cena 1.

ANDRÉ: Teve uma época, isso foi antes da loja, quando eu trabalhava de empacotador no supermercado, que é outra coisa que não precisa pensar muito, que eu só pensava em ser famoso. Normalmente eu pensava em ser famoso jogando futebol. Ficava imaginando mil gols maravilhosos que eu fazia, um mais decisivo que o outro.

\section{CENA 38 - ARQUIVO/DESENHOS}

André jogando futebol, torcida vibrando num estádio lotado. Desenhos dos esquemas dos gols. (...)

\section{CENA 39 - ARQUIVO}

Imagens de arquivo: Pelé comemorando vários gols. Reinaldo comemorando um gol. Romário comemorando um gol. (...)

Uma mulher aparece no meio do campo de futebol.

MULHER: Você podia tirar o azeite de cima das frutas?

CENA 40 - SUPERMERCADO - INTERIOR/DIA

André no supermercado, no caixa. A sua frente, a Mulher irritada.

ANDRÉ: Como?

MULHER: A lata de azeite. É pesada, você colocou em cima das frutas. Põe o azeite junto com as caixas.

ANDRÉ: Desculpe.

A superposição de planos em colagem também se dá em relação a diferentes linguagens presentes no filme:

- colagem de cenas do filme e das histórias em quadrinhos produzidas por André: o personagem Zeca Olho na escola e a lição sobre o descobrimento do Brasil, ou ainda a cena do assassinato de Feitosa;

- colagem da história do filme com cenas de desenho animado, como ocorre na seqüência em que o personagem vó Doutrina acompanha 
Zeca Olho à escola para devolver a Mairoldi o dinheiro que este havia emprestado ao neto;

- colagem intricando o diálogo do filme e cenas de um noticiário na televisão: na cena 164, André anuncia à mãe uma viagem que fará à Holanda, entremeando sua conversa com o texto de uma notícia sobre um leão marinho localizado no praia do Cassino;

- colagem de conversas cotidianas e texto literário (poema de Shakespeare).

Em meio a tantas superposições e interferências de séries, não há certamente lugar para o sujeito centrado. Quando tal acontece, ou seja, quando surge em cena algum personagem que atualize (ainda que remotamente) uma "vocação para o centramento", sua desqualificação é certa, como é o caso da família bolha ${ }^{7}$ (Gomide, patrão de André na papelaria, sua mulher e seu filho) e de Antunes (pai de Sílvia), personagens sempre iguais a si mesmos. Valorização, portanto, dos mosaicos, das diferentes colagens, no que concerne ao tempo, ao espaço, à construção do perfil dos personagens e do próprio sentido de ação.

\section{Deslocamentos Rumo a Outros Modos de Existência}

Com base em Hall (2000), podemos acompanhar alguns dos deslocamentos por que passa ao longo do tempo o sujeito da Modernidade, deslocamentos que compreendem a transição de uma posição de maior centramento (o sujeito individual, o "indivíduo soberano", possuidor de uma identidade) para uma posição de maior descentramento na Modernidade tardia. Com efeito, ao sujeito do iluminismo, centrado numa identidade estabilizada e individualizante, assistimos, no século XIX, à entrada em cena de uma concepção sociologizante de sujeito, a qual reflete "a crescente complexidade do mundo moderno e a consciência de que este núcleo interior do sujeito não era autônomo e auto-suficiente ..." (Hall, 2000, p.11).

\footnotetext{
A designação "bolha” para se referir a toda a família de Gomide, patrão de André na papelaria, se justifica pelo fato de este haver instalado num ponto estratégico da loja um espelho curvo (dito "espelho-bolha") para lhe facilitar o controle de tudo o que ali se passa, de todas as ações dos empregados.
} 
O que Hall (2000, p.11) chama de "uma concepção 'interativa' da identidade e do eu" decorrente dos trabalhos em sociologia, em especial as contribuições do interacionismo simbólico, inclui-se no referido processo de descentração da noção de sujeito: explicita-se o hiato existente entre o eu (interior) e a sociedade (exterior), e a identidade será o que vai procurar preencher tal distância. Como se percebe, apesar dos esforços empreendidos por tal visão sociológica no sentido de superar um modelo de sujeito essencialmente individualizado, localizando o indivíduo "em processos de grupo e nas normas coletivas" (Hall, 2000, p.31), permanece a cisão (de inspiração cartesiana) entre indivíduo e sociedade ${ }^{8}$.

Se é verdade que uma concepção mais social do sujeito veio contribuir para desestabilizar o modelo do sujeito da razão, é fato também que certos deslocamentos operados por força das teorias sociais acabaram por exercer um maior impacto em tal desestabilização. Hall cita "cinco grandes avanços na teoria social e nas ciências humanas ... e cujo maior efeito ... foi o descentramento final do sujeito cartesiano" (Hall: 2000, p.34), a saber: o pensamento marxista, a descoberta do inconsciente por Freud, a concepção de língua em Saussure, as reflexões de Foucault sobre o poder disciplinar e, finalmente, o impacto do feminismo como movimento social.

Para as finalidades deste artigo, limito-me a refletir sobre as conseqüências dos dois primeiros grandes descentramentos, o sujeito da ideologia discutido em Marx e o sujeito do inconsciente freudiano. A razão que me leva à escolha desses dois momentos de descentramento é simples: temos em Marx e em Freud (e em sucessivas leituras que deles se fizeram) as bases de uma abordagem discursiva nos moldes do que se desenvolveu sob a denominação de "Análise do discurso" a partir de Pêcheux, no final da década de sessenta do último século.

Com Marx, assiste-se ao declínio do indivíduo como agente da história, tendo em vista o importante papel desempenhado pelo conceito de ideologia em sua reflexão. Trata-se sem dúvida da descentração em relação a qualquer idéia de "essência do humano" e da possibilidade de entender a

\footnotetext{
8 Hall (2000, p.30-31) faz ainda referência a dois outros eventos do século XIX que contribuíram para a manutenção do efeito de centramento do sujeito: a ratificação da cisão entre mente e corpo possibilitada pela biologia darwiniana (a mente passava a ter um fundamento localizado fisicamente no cérebro); a divisão, no âmbito das ciências sociais, entre a psicologia (discipina especificamente dedicada ao estudo dos processos mentais do indivíduo) e as outras disciplinas.
} 
ação dos homens como resultante de um projeto intencional do qual seriam seus efetivos "agentes". Mais recentemente, na leitura feita por Althusser, explicita-se a natureza do trabalho realizado pela ideologia: interpelar os indivíduos concretos como sujeitos, função que Pêcheux procurará apreender por intermédio da noção de assujeitamento. No mesmo sentido parecem caminhar os trabalhos de Freud com o inconsciente, os quais denunciam uma lógica subjacente a nossos atos que nada tem a ver com o que move o sujeito da razão.

Temos, assim, um eu, resultado da interpelação do indivíduo em sujeito, na ótica marxista desenvolvida por Althusser; e também um eu, aparelho de regulação e de adaptação à realidade em oposição ao id e ao superego, segundo Freud. Este sujeito é visto como objeto das influências externas (sociais, culturais, políticas, econômicas) e, por isso, facilmente manipulável (Veiga-Neto, 2003, p.135). Seria preciso, então, para libertar-se da alienação ideológica (Marx) ou das fixações traumáticas da infância (Freud), construir um caminho de autoconsciência e de conquista de sua "soberania".

Em $O$ homem que copiava, não é apenas a imagem de maior centramento do sujeito da razão que se desqualifica. Ao contrário, desqualificam-se também essas primeiras formas de descentração do sujeito, a saber, a decorrente da perspectiva marxista e dos trabalhos de Freud.

A desqualificação da ênfase concedida à concepção de sujeito ideológico pode ser argumentada por vários caminhos. Optamos aqui por trazer a voz de Foucault:

A noção de ideologia me parece dificilmente utilizável por três razões. A primeira é que, queira-se ou não, ela está sempre em oposiz̧ão virtual a alguma coisa que seria a verdade. Ora, creio que o problema ... (é) ver historicamente como se produzem efeitos de verdade no interior de discursos que não são em si nem verdadeiros nem falsos. Segundo inconveniente: refere-se necessariamente a alguma coisa como o sujeito. Enfim, a ideologia está em posição secundária com relação a alguma coisa que deve funcionar para ela como infra-estrutura ou determinação econômica, material, etc. (Foucault, 1986, p. 7).

Quanto à desqualificação desta forma de descentramento que consiste no modelo de inconsciente formulado por Freud, retomamos muito sinteticamente a reflexão de Deleuze e Guattari:

A grande descoberta da psicanálise foi a da produção desejante, a das produções do inconsciente. Mas, com o Édipo, essa descoberta foi rapidamente ocultada por um novo idealismo: substi- 
tuiu-se o inconsciente como fábrica por um teatro antigo; substituíram-se as unidades de produção inconsciente pela representação; substituiu-se um inconsciente produtivo por um inconsciente expressivo (o mito, a tragédia, o sonho ...). (Deleuze \& Guattari, s/d., p.23)

Com efeito, segundo Naffah Neto (1985), temos em Freud a "idéia de que o espaço social-político-econômico-cultural é um espaço caracterizado por relações objetivas e visíveis, estruturado por identidades estáveis e atravessado por significações mais ou menos transparentes", "espaço sublimado e organizado onde o desejo já renunciou aos objetos parciais, aos seus fluxos e intensidades semoventes para institucionalizar-se numa forma de realidade cristalizada". Tal universo é visto como produto, e não como produção, restando, desse modo, como alternativa, deslocar o plano da produção "para um espaço psicológico, que, como espaço segregado, invisível, é o único capaz de comportar fenômenos deslocantes, mutantes, irradiados." (Naffah-Neto, 1985, p. 21-22). Como veremos adiante, é contra essa concepção de social visto como lugar de realidades objetivas e transparentes que se insurgirão alguns pensadores, os quais contribuirão para se repensar a produção de subjetividade.

\section{Que Concepção de Subjetividade Assumir?}

Tendo em vista o que acabamos de explicitar, o que fazer dos conceitos de ideologia e inconsciente? Como repensar a questão do sujeito em novas bases que nos permitam tematizar simultaneamente, numa visão não essencialista, aquilo que o condiciona e o que é por ele escolhido, aquilo que muda e o que permanece em suas relações com o mundo?

Iniciemos pela reflexão voltada para o conceito de ideologia. Trata-se, segundo a opção que ora fazemos, de um conceito a ser substituído, nos moldes indicados em Guattari \& Rolnik (1986, p.25): "Ao invés de ideologia, prefiro falar sempre em subjetivação, em produção de subjetividade. (...) Proponho ... a idéia de uma subjetividade de natureza industrial, maquínica, ou seja, essencialmente fabricada, modelada, recebida, consumida".

Eis, portanto, o modo pelo qual se desqualifica a noção de ideologia:

... eu diria que, assim como se fabrica leite em forma de leite condensado, com todas as moléculas que lhe são acrescentadas, injetam-se representações nas mães, nas crianças - como parte do processo de produção subjetiva. (...) 
Todas essas questões da economia coletiva do desejo deixam de parecer utópicas a partir do momento em que não mais consideramos a produção de subjetividade como sendo apenas um caso de superestrutura, ... A partir do momento em que consideramos a produção de subjetividade como sendo a matéria-prima da evolução das forças produtivas em suas formas mais desenvolvidas (os setores "de ponta" da indústria). (Guattari \& Rolnik, 1986, p.25-26)

No que concerne ao conceito de inconsciente, a solução será outra: se rejeitamos, com Guattari \& Rolnik, a idéia de ideologia, manteremos a de inconsciente, mas não sem repensá-la em termos não freudianos. Desse modo, à interioridade do modelo personológico, familiarista, do inconsciente freudiano, lugar de fixações arcaicas do passado (narcisismo, instinto de morte, medo à castração), Guattari preferirá um inconsciente desterritorializado, um inconsciente dito "maquínico" ou "esquizoanalítico", permeável às instituições e às forças do campo social, voltado tanto para o presente, para o passado quanto para o futuro; um inconsciente concebido como lugar de interação entre componentes semióticos e sistemas de intensidade diversificados, e não um inconsciente eminentemente representacional, um "inconsciente-descarga" freudiano; enfim, um inconsciente cujos mapas diagramáticos de intensidades e fluxos ${ }^{9}$ são sempre singulares e, portanto, refratários a quaisquer iniciativas de modelização ${ }^{10}$ :

... Inconsciente, então, mais 'esquizo', liberado dos grilhões familialistas, mais voltado para práxis atuais do que para fixações e regressões em relação ao passado. Inconsciente de Fluxo e de máquinas abstratas, mais do que inconsciente de estrutura e de linguagem. (Guattari, 1992, p.23).

Do duplo movimento resultante das reflexões acerca de ideologia e inconsciente, vemo-nos confrontados com uma nova possibilidade de conceber a subjetividade:

... a definição provisória mais englobante que eu proporia da subjetividade é: "o conjunto das condições que torna possível que instâncias individuais elou coletivas estejam em posição de emergir como território existencial auto-referencial, em adjacência ou em relação de delimitação com uma alteridade ela mesma subjetiva. (Guattari, 1992, p.19)

\footnotetext{
9 Por fluxos entendemos aqui justamente os componentes (materiais, energéticos, semióticos, tecnológicos) situados aquém da individualização de sujeitos ou objetos e cujos encontros, em combinações variadas, facultam devires que atualizam outras formas de sentir, pensar e agir.

10 A caracterização do duplo modelo de inconsciente que ora apresento foi elaborada tomando-se por base elementos localizados em Guattari $\left(1985^{\mathrm{a}}\right.$, p.166-171).
} 
Eis, desse modo, explicitado o interesse da posição defendida por Guattari para aqueles que trabalham com as práticas de linguagem: a diversidade do que o autor denomina "vetores de subjetivação".

Guattari define a subjetividade como o conjunto das relações que se criam entre o indivíduo e os vetores de subjetivação que ele encontra, individuais ou coletivos, humanos ou inumanos. Abertura decisiva: procurava-se a essência da subjetividade no sujeito, e este é visto como irremediavelmente descentrado, imerso em "regimes semióticos a-significantes"11 ... (Bourriaud, 1994, p. 82)

Trata-se, pois, de um modelo de subjetividade processual que coloca a ênfase no fluido, no molecular:

Quais são esses significantes fluidos que compõem a produção de subjetividade? Primeiramente, o meio cultural ("a família, a educação, o meio, a religião, a arte, o esporte"); a seguir, o consumo cultural ("os elementos fabricados pela indústria midiática, do cinema, etc."), gadgets ideológicos, peças destacadas da maquinaria subjetiva ... E enfim, o conjunto das maquinarias informacionais, que forma o registro a-semiológico, a-lingü̈́stico, da subjetividade contemporânea, por funcionarem paralela ou independentemente do fato de produzirem significações." (Bourriaud, 1994, p. 82)

Uma subjetivação, portanto, multidirecional que não abre mão de sua inscrição em um projeto de ecosofia (Guattari, 1990) - noção pela qual Guattari ratifica a indissociabilidade de três frentes de ação ecológica, a saber, uma ecologia do meio ambiente, do social e das mentes:

A maioria dos ecologistas ainda não percebeu a necessidade de reunir a ecologia ambiental, a ecologia social e a ecologia mental, porque, com efeito, tudo se interliga: não se pode esperar remediar os ataques ao ambiente sem modificar a economia, as estruturas sociais, o espaço urbano, os hábitos de consumo, as mentalidades. Quando se abordam ecossistemas humanos, confrontamo-nos necessariamente com componentes associais, políticos, com sistemas de valor moral, estético ... (...) Seria necessário levar em consideração, por exemplo, hoje, que não estão ameaçadas apenas espécies animais ou vegetais, paisagens naturais, mas também espécies culturais, como o cinema de autor, espécies morais, como os valores de solidariedade e de internacionalismo e, mais profundamente, "espécies existenciais", como a propensão não apenas a aceitar, mas a amar a diferença em relação a uma renovação do gosto da vida, da iniciativa, da criatividade. (Guattari, 1994, p.97-98)

\footnotetext{
11 Tradução nossa, procedimento que adotaremos em relação a todos os textos citados que se encontram originalmente em língua estrangeira.
} 


\section{Modos de Subjetivação em O Homem que Copiava}

Do ponto de vista da produção de subjetividade, $O$ homem que copiava apresenta-se como obra muito compatível com as críticas a Freud e a Marx que acabamos de apresentar. Com efeito, assistimos no filme a reiteradas situações nas quais se aponta como caminho de produção de sentido a superação de um "raciocínio por equações" do seguinte gênero: se alguém pertence a uma classe social x, então agirá da forma x'; ou então, se alguém participa de uma condição familiar y, isso propiciará um comportamento y'; a ação de um dispositivo $\mathrm{z}$ da ordem do inconsciente favorece uma configuração z', etc.

O homem que copiava não ratifica tais expectativas: André está longe de ser o mero efeito de inserção em uma dada classe social, ou em uma dada conformação familiar. À guisa de exemplo, reproduzo um dos momentos do enredo do filme em que se percebe a ineficácia dos parâmetros de um modelo de inconsciente freudiano sobre o personagem, enfatizando a naturalidade ("desdramatizada") com que André relata a perda do pai:

CENA 25 - SALA DE ANDRÉ - INTERIOR/NOITE

André-Criança está sentado em frente a uma televisão.

ANDRÉ (VS): Meu pai foi embora quando eu tinha quatro anos. Essa é a parte do destino. Eu estava vendo um programa de televisão.

CENA 26 - SEQ. DE MONTAGEM / ARQUIVO

Imagens de arquivo da família Trapo. Cópia - na máquina, da capa do livro "A Vida, Modo de Usar": ilustração de um prédio sem uma das paredes, revelando o interior dos apartamentos.

ANDRÉ (VS): O cenário era uma casa cortada ao meio, sem as paredes para a gente poder ver dentro. Vi a capa de um livro que era assim.

CENA 27 - SALA DE ANDRÉ - INTERIOR/DIA

O Pai de André, na porta do apartamento.

PAI: Guarda a correspondência para mim?

ANDRÉ: A-hã.

André-Criança guarda correspondências em caixas.

ANDRÉ (VS): Ele não recebia muita carta, era mais cobrança e anúncio de um monte de coisas. Eu guardava tudo numa caixa de camisa. Depois a caixa ficou pequena e eu passei tudo para uma caixa de sapato. Depois para três caixas, dividindo as cobranças, os anúncios e as cartas.

O mesmo poderia ser dito a respeito da personagem Sílvia e seu projeto (absolutamente desprovido de culpa) de assassinar o pai, Antunes, o 
qual se interpõe, por intermédio de chantagens, à consecução dos objetivos por ela pretendidos: havendo descoberto que André era o assaltante do carro-forte que o havia agredido, Antunes exige-lhe parte do dinheiro roubado para não denunciá-lo à polícia. A solução encontrada por Sílvia para o problema, a saber, matar o pai, será posteriormente executada:

[Sílvia e André Ficam se olhando, alguns segundos.

SÍLVIA: Eu prefiro matar ele.

ANDRÉ: Ele é seu pai.

SÍLVIA: E aí?

ANDRÉ: Como, e aí? Você não pode matar seu pai.

SÍLVIA: Por que não?

ANDRÉ: Porque ele é seu pai. Sem ele, você não existia.

SÍLVIA: Gratidão. É isso? Eu tenho que ser eternamente grata a ele por ter dormido com a minha mãe, há trinta anos. Ele nem queria que ela me tivesse. E ela queria que eu não fosse dele. Ela era louca por outro cara, um lindo. Ela tinha uma foto dele, que ela recortou do jornal. Ele era artista. Se mudou para o Rio. Minha mãe achava que eu era filha dele. Eu também acho. Mas ele foi embora. Ela estava noiva. Casou. Ela morreu moça, quarenta e dois. Fumava muito. Ele é um escroto. Você acredita que ele me espia pelo buraco da fechadura quando eu entro no banho?

ANDRÉ: Acredito.

SÍLVIA: E eu posso matar ele, sim.

Sílvia volta para a cama.

SÍLVIA: Esse dinheiro é seu. Vamos matar ele e fugir. Para o Rio. (...)

Como vemos, os personagens configuram-se, antes, como uma "mistura turbulenta" de suas invenções com os objetos com os quais produzem agenciamentos diversos, uma mistura do modo como fazem ressoar os enunciados que lhes chegam, de suas paixões, projetos, etc. Percebemos que André não é nem agente (sujeito da consciência que arquiteta uma vida, o 'eu' pensante), nem paciente (produto previsível de uma certa inserção em uma classe social, de um dado exercício profissional, de uma dada posição na família, etc.) em suas relações com o mundo: é o encontro de forças (mutantes) que o atravessam e o constituem em sua singularidade, profundamente implicado com as conexões que é capaz de promover; sujeito como efeito dos encontros que faz, e nunca como forma-consciência resultante de uma ideologia e um inconsciente; dito de outro modo, efeito-sujeito que coincide com o modo como vive as forças que se atualizam em diferentes níveis de intensidade. Efeito como resultado das 
dobras ${ }^{12}$ que o constituem (sempre provisoriamente) como sujeito, que se fazem e se (re)/(des)fazem incessantemente, atualizando o projeto defendido por Guattari (1992, p.21): “... fazer transitar as ciências humanas e as ciências sociais de paradigmas cientificistas para paradigmas éticoestéticos...".

\section{Ultrapassar o Modelo Representacional Macro do Marxismo e do Freudismo?}

Conquanto percebamos que o recurso a Marx e a Freud apresenta o mérito de nos afastar do modelo de sujeito cartesiano da razão, não pretendemos permanecer, no que diz respeito à produção de subjetividade, em tais formas de descentramento que nos parecem manter ainda um compromisso (indesejável) com uma certa visão essencialista de sujeito.

Com efeito, o compromisso do homem da razão é a manutenção de determinadas "formas de essência" que pretensamente dariam conta do real - um real naturalizado. Em conformidade com tal plano do real no qual os corpos são vistos como essências, André é ... ladrão, assaltante, falsário, etc. ... enfim, André é!

Pelo recurso aos planos do ideológico em Marx e do inconsciente freudiano, já nos deslocamos de tal perspectiva naturalizada (em seu sentido forte), mas ainda permanecemos presos ao plano das representações e a uma relação de causalidade excessivamente linear que nos leva a produzir "ideais de subjetividades" como o sujeito não alienado, em Marx, ou o sujeito liberado de seus fantasmas do passado, em Freud. Assim, teríamos: "André foi expulso da escola, ingressou no mundo da contravenção e do crime, porque pertencia a uma classe desfavorecida, porque era agressivo, porque não teve na infância um modelo de pai, porque ...".

O caminho que ora queremos oferecer como alternativa a tais limitações é este: com base no conceito de dobra, resgatar a dimensão da acontecimentalização. Explico-me. Como vimos anteriormente, a noção de dobra ajuda-nos a pensar os processos de subjetivação pelo fato de explicitar o

12 Conceito deleuziano que remete aos modos de produção de subjetividade: produção de um dentro e de um fora que se traçam por linhas instáveis e turbulentas, revestida de uma dimensão política por se contrapor à noção (identitária) de um interior e um exterior absolutos. 
que há de perspectivo e de transitório na produção dos territórios, por nos fazer ver quão frágil é a membrana que delimita o espaço do dentro visto como estado passageiro do fora. Tal modo de conceber a articulação entre o dentro e o fora se contrapõe à proposta de identidades apreendidas como essências: os corpos passam a ser vistos como pura relação de força. A dobra se harmoniza com a noção de acontecimento, pois reenviam ambas ao mesmo trabalho de desnaturalização:

A acontecimentalização consiste em reencontrar as conexões, os encontros, os apoios, os jogos de força, as estratégias, que têm, em um momento dado, formado o que, em seguida, vai funcionar como evidência, universalidade, necessidade. (Martins, 2002, p. 89-90)

Como apreender este plano dos jogos de força responsáveis pela conformação de sucessivos estados de corpos em $O$ homem que copiava?

Diremos que acontecimentalizar algo significa reencontrar as forças que foram aos poucos se apagando e que, posteriormente, determinaram que fosse percebido como absolutamente natural ou evidente o nexo de saber-poder ${ }^{13}$ responsável pela configuração de uma forma estabilizada qualquer. Assim, em $O$ homem que copiava, a desnaturalização de um dado estado de coisas com o qual deparamos (um André fotocopiador, pobre, não escolarizado, dito "otário e cagalhão", suporte de poderosa máquina desejante que o move à ação, etc.) não pode ocorrer por intermédio da simples (simplista?) inserção do personagem em uma classe social e em uma estrutura familiar. Ao contrário, penso que a acontecimentalização deva remeter a uma estranha equação (não exatamente matematizável), na qual entra em cena uma grande variedade de semióticas significantes e a-significantes: sonhos do protagonista + fotocopiadora nova a cores + salário aviltado + habilidades do ilustrador + binóculo + gravuras pré-

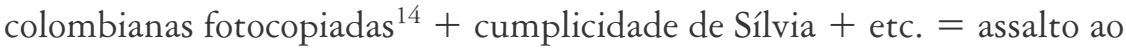
carro-forte, assassinato de Feitosa e do policial, realização de desejos, etc. Equação que nos ajuda a ver os corpos como puras relações de força (e não mais como essências) nas quais se atualizam diferentes agenciamentos de fluxos:

\footnotetext{
13 Em Rocha (mimeo) é explorado justamente o tema dos saberes e poderes na produção de agenciamentos coletivos de enunciação em $O$ bomem que copiava.

14 A importância das gravuras a que me refiro justifica-se pelo fato de uma delas representar traços verticais no interior de um triângulo, lembrando justamente o dispositivo arquitetado por André para matar Feitosa, a saber, varas de madeiras espetadas (e camufladas) num monte de areia sobre as quais o personagem cairia, morrendo atravessado pelas mesmas.
} 
- fluxos de produção, reunindo, de um lado, a rotina imbecilizante do trabalho de um operador de fotocopiadora e, de outro, a disrupção proporcionada pela invenção de algo para além dessa mesma rotina (sendo a produção de cédulas falsas um deslocamento que se opera em sua relação com a máquina), ou ainda a disrupção presente no "ofício de ilustrador";

- fluxos de desejo e de sonho: conquistar Sílvia; ser famoso e rico; tornar-se um ilustrador;

- fluxos técnicos, responsáveis pela atualização de um personagemmáquina fotocopiadora; personagem-binóculo, o homem-luneta ou o patrão-bolha;

- fluxos econômicos, que inscrevem o personagem em uma lógica de classe social, de relações com o mundo do trabalho assalariado, sendo seu refrão o seguinte: "O negócio é ficar rico logo, o mais rápido possível, e se mandar";

- fluxos semióticos, nos quais se conjugam modos de expressão que vão muito além do verbal: os quadrinhos, os desenhos de animação, os recortes para colagem;

- fluxos verbais de ordem variada, a começar pela diversidade de gêneros de discurso que se misturam no filme: texto literário (soneto de Shakespeare), textos científicos, histórias de ficção, relato de aventura, conversações cotidianas, etc.;

- fluxos de culpabilização que percorrem todo o filme: André é "o cagalhão, o otário", segundo a perspectiva de Feitosa;

- fluxos psíquicos, a exemplo do modo (paradoxal) como André lida com a adjetivação que lhe é atribuída: por um lado, sente-se um otário, sim, pelo salário que lhe é pago ("O Bolha pensa que eu sou otário. Considerando o que ele me paga, ele não deixa de ter uma certa razão"); por outro, distancia-se da imagem de otário quando avalia a situação da morte de Feitosa ("Cagalhão eu até posso ser, mas otário eu não sou. Eu disse que era perigoso pular. Mesmo sem as varas dentro da areia, era perigoso pular.");

- fluxos familiares que inscrevem André no interior de uma dinâmica em que se vê associado à mãe, na ausência de um pai que o abandona ainda na infância, sem que seu desaparecimento deixe no personagem qualquer marca evidente de uma situação traumática. 
O que o personagem pode ver e dizer, os modos de subjetivação que atualiza, são resultados da conjugação de tais fluxos e da possibilidade de amalgamá-los em linhas de segmentaridade (de consistências variadas) e em linhas de fuga. Trata-se, com efeito, da produção de um certo modo de subjetivação cujo mérito reside em descartar tanto uma concepção de sujeito que pressuponha algum grau de determinismo do sujeito (o "sujeito assujeitado" da ideologia e do inconsciente freudiano) quanto uma concepção mais "voluntarista", "subjetivóide", segundo a qual o sujeito tomaria decisões, faria escolhas, livre da intervenção de quaisquer fatores. A respeito da inadequação também desse último modelo, retomo, a título de exemplo, a reflexão de Machado \& Lavrador:

Por mais que se faça presente um 'eu decido', 'eu acredito', 'eu escolbo', 'eu desejo', estas expressões apontam para pensamentos e valores que são produzidos historicamente. Trata-se da constituição, dentre tantas outras possíveis, de uma certa forma subjetiva ou de 'subjetividades intimistas'. O desejo, apontado como instância maior de uma efetiva afirmação do 'eu', de uma marca da personalidade, de uma autenticação de si, acaba prisioneiro de uma identidade que diz muito mais respeito ao consumo, à massificação, do que aos processos de expressão e de criação de diferenças e de 'singularidades'. Pensar que a afirmação dos próprios valores, das próprias decisões ... demarcaria necessariamente a afirmação de que ... 'eu sou único'... seria acreditar que a singularidade é prisioneira do 'eu'. Contudo, a rede de forças que nos perpassa ... nos faz acreditar que o 'eu' que se quer 'aprisionador' é muito mais prisioneiro de uma forma subjetiva que se pretende hegemônica e espraia sua dominação até a criação de desejos 'intimistas'. (Machado \& Lavrador, 2000, p.307-308).

Com toda a certeza, esse tipo de formulação parece trazer algo de mais interessante do que as meras determinações de classe, por exemplo, ou ainda as marcas do inconsciente-teatro de representações de um passado. Já não diremos agora que André é seja lá o que for; diremos, antes, que André devém ... múltiplo, em função dos diferentes agenciamentos de que participa.

\section{Implicações com o Trabalho sobre as Práticas Linguageiras}

Dentre as conseqüências de todas essas reflexões para os estudos das práticas linguageiras, apenas destaco quatro pontos, que poderão ser desenvolvidos em outra oportunidade: as noções de subjetividade, condições de produção, enlaçamentos e prática discursiva. 
Em primeiro lugar, direi que o debate voltado para a noção de sujeito tem sido uma preocupação no campo dos estudos das práticas linguageiras, a exemplo dos trabalhos de Possenti $(2002)^{15}$, Brait $(2001)^{16}$, Gregolin (2004), Orlandi (2001).

As reflexões que ora apresento sobre a questão do sujeito podem ser produtivas a ponto de repercutirem em outras noções com que vimos trabalhando numa perspectiva discursiva. Com efeito, alterar a compreensão de sujeito e de seu modo de relacionamento com um dado entorno (relacionamento que, nos moldes de Deleuze, não será nem de assujeitamento, nem de simples realização de intenções) significa alterar o modo como vemos a relação do texto com seu "ambiente". Ora, tal debate não é outro senão o relativo ao que classicamente conhecemos como "condições de produção dos discursos".

A noção de condições de produção encontra-se já presente nas investigações em psicossociologia do início do século XX. Em seus primórdios, assentada na perspectiva dos trabalhos em Análise de Conteúdo, o conceito de condições de produção remetia à depreensão de relações entre estruturas lingüísticas (o texto, plano horizontal) e estruturas psicológicas e sociológicas (plano vertical). O texto era então considerado como um "reflexo", mais ou menos transparente, mais ou menos imperfeito, dessa realidade psicológica ou sociológica. Em breve síntese, após passar por um referencial teórico da Sociolingüística nascente dos anos 60, diremos que a noção vem a ser ressignificada em Pêcheux, que remodelerá o circuito de comunicação jakobsoniano, preconizando que "o que funciona nos processos discursivos não são 'organismos humanos individuais' que falam a respeito de objetos do mundo físico, mas formações imaginárias que designam o lugar que o emissor e o destinatário atribuem a si mesmos e ao outro (imagem que constroem para si de seu próprio lugar e do lugar do outro), sustentando pontos de vista acerca de um referente que também participa das condições de produção do discurso na condição de objeto imaginário" (Rocha \& Deusdará, 2006). Uma tensão aqui se institui: por um lado, ganha destaque o tema do assujeitamento ideológico; por outro, uma microssociolo-

\footnotetext{
15 Em Possenti (2002), o autor reúne vários artigos que tematizam o assujeitamento e as margens de manobra do sujeito.

16 A obra citada é especialmente relevante por reunir uma série de contribuições de diferentes autores preocupados com a problemática do sujeito.
} 
gia das interações vem reivindicar algum grau de liberdade para as manobras desse sujeito. Com o desenvolvimento ulterior dos trabalhos, chega-se à evidência de que, dentre as condições de produção de um texto, existem as decorrentes da própria situação de comunicação, assim como as de ordem do conteúdo discursivo, que, segundo Charaudeau \& Maingueneau (2004, p.115), incluem os saberes pré-construídos que circulam no interdiscurso ${ }^{17}$.

O homem que copiava revelou-se uma excelente oportunidade para a reflexão acerca do tema da produção de subjetividade e das "condições de produção" dos discursos. Vimos, com efeito, que não podemos separar o personagem e seu entorno (incluindo-se na idéia de entorno tanto as paisagens como os objetos e demais personagens da história, a ponto de entendermos como mais adequada a referência a um personagem-binóculo, ou um personagem-fotocopiadora, e nunca a consideração de meras identidades estanques). Os acoplamentos são, decerto, variados: André não seria o mesmo sem a paisagem da vizinhança que é capaz de apreender todas as noites da janela de seu quarto, assim como se torna uma mistura indissociável o encontro de André-Cardoso-loteria, ou André-Sílvia-assassinato de Antunes, etc.

Por colocar em cena um modo de articulação entre os discursos e seu entorno, o debate acerca da noção de condições de produção encontra ressonâncias importantes no conceito de território, o qual será pensado, retomando a posição de Elkaïm \& Stengers (1994, p.149), como algo que excede simultaneamente o organismo e o meio, implicando um agenciamento. Qual a relevância do que dizem os autores citados para a discussão das implicações com as práticas linguageiras? Em outras palavras, qual a importância da aproximação do conceito de território para repensar as condições de produção dos discursos? De modo sintético, direi apenas o seguinte:

- primeiramente, o resultado do encontro de um organismo com o seu meio é muito mais poderoso do que a mera soma das partes;

- a seguir, organismo e meio (leia-se também: o sujeito e seu outro, ou os discursos e seu entorno) não são identidades apriorísticas, mas

17 Para um maior detalhamento desse trajeto, ver Rocha \& Deusdará (2006). 
fruto de um trabalho que se realiza por meio de acoplamentos singulares, de encontros nos quais forças colidem gerando formas em constante alteração.

Resta apontar o interesse da presente reflexão no que diz respeito aos conceitos de enlaçamentos e prática discursiva, os quais se referem respectivamente aos "processos pelos quais o texto de uma formação discursiva reflete sua própria enunciação" (Maingueneau, 1989, p.69) e à "reversibilidade essencial entre as duas faces, social e textual, do discurso" (Maingueneau, 1989, p.56).

Não é difícil perceber a afinidade desses dois conceitos com todas as questões que vimos levantando até o momento. Afinal, ambos falam, cada um à sua maneira, do encontro entre o texto e seu entorno: no caso dos enlaçamentos, o modo como se interlegitimam enunciado (texto) e enunciação (elementos referentes a uma dada "conformação de mundo" no qual se produz aquele enunciado); no caso das práticas discursivas, o modo como se articulam os discursos (que dão visibilidade aos sujeitos) e as comunidades discursivas (que dão sustentação a esses discursos).

A insistência de ambos os conceitos no tema dos encontros produzidos entre o texto e seu entorno os aproxima da problemática das condições de produção e do modo como concebemos a produção de subjetividade. Algo, portanto, se evidencia como tendência maior: a recusa de toda e qualquer concepção que erigiria em absoluto a relação entre um interior e um exterior. Com efeito, assim como a produção de um dado modo de subjetivação remete à dobra (sempre provisória) do fora, e não a qualquer "eu" essencializado, da mesma forma o enunciado não se coloca em posição de exterioridade em relação ao mundo do qual ele fala. O enunciado é, antes, a contrapartida de um dado estado de coisas que resulta dos "arranjos caleidoscópicos" de mundos que se sucedem. Ou ainda: o enunciado não "diz o mundo"; antes, pelo modo como é produzido, acopla-se ao fora, "mimetizando" esse entorno e, em troca, é por esse mesmo entorno legitimado: "desde sua emergência, a palavra supõe uma certa situação de enunciação, a qual, com efeito, é validada progressivamente por meio dessa mesma enunciação", segundo Maingueneau (2006).

Vimos que $O$ homem que copiava falava de um mundo de cópias e repetições, de uma vida em luta para não reproduzir o mesmo. Pois bem, esse mesmo "enredo" pode ser recuperado no plano enunciativo: produção de 
uma narrativa fragmentada, num tempo entrecortado e ritmado por uma lógica de associação de fragmentos em mosaico, de espaços que se superpõem e se misturam, amalgamando diferentes planos de realidade; bricolagem com uma grande diversidade de gêneros, transitando-se de um para outro sem qualquer aviso prévio: da conversação cotidiana que se trava entre os personagens ao desenho animado ou aos quadrinhos, passando-se pelo texto literário, pelos discursos técnicos ou ainda por estilhaços de discurso científico (ou de vulgarização científica). Retomando a tipologia apresentada por Maingueneau (1989, p.69), vemo-nos no filme confrontados a enunciados de quarto grau, a saber, textos nos quais "a descrição do mundo é, a um só tempo, definição de um ideal enunciativo e percurso de uma instituição".

A fragmentação a que me refiro acaba se manifestando no próprio plano dos signos verbais. Com efeito, não é raro deparar com um certo "encantamento" dos personagens diante de "estilhaços de sonoridades" que não chegam propriamente a remeter a nenhuma idéia (pelo menos não a nenhuma idéia suficientemente clara). Tais "fracionamentos do signo" permanência apenas da imagem acústica, desaparecendo o conceito - podem ser localizados no destino reservado a termos como doutrina (palavra descoberta por André por ocasião da fotocópia de texto que falava acerca da doutrina Roosevelt) ou birsuta (termo presente no poema de Shakespeare que o personagem fotocopia): doutrina, palavra que lembra a André "nome de velha", será o significante escolhido para nomear um dos personagens da história em quadrinhos que ele desenha ("vó Doutrina"); hirsu$t a$, por sua vez, se tornará o nome da professora, outro personagem dos quadrinhos de André ("Dona Hirsuta"). Acrescente-se ainda, numa mesma lógica de fragmentação dos signos lingüísticos em $O$ homem que copiava, a magia que exerce sobre os personagens a sonoridade do nome da cidade holandesa "den Haagen".

Como se percebe, indicamos algumas articulações como relevantes para o estudo das práticas linguageiras, mas, como o dissemos, apenas as afloramos. Resta investir em sua produtividade no referido campo de estudos, razão pela qual apresentamos uma última reflexão que poderá gerar frutos no tratamento deste tópico voltado para os encontros (sempre problemáticos) entre o texto e seu entorno: a reflexão de Deleuze (1987) sobre fenômenos da ordem da enunciação em $A$ la recherche du temps perdu. Trata-se de leitura da obra de Proust que explicita o absoluto intricamento 
entre o narrador que assume a enunciação e a própria Recherche enquanto mundo do qual se fala: recusa de qualquer relação de exterioridade entre sujeito da enunciação e sujeito do enunciado e, conseqüentemente, valorização de uma máquina que não trabalha sob o modo da produção de identidades estabilizadas. Deleuze aproxima, então, numa imagem que desperta felizes ressonâncias, esse narrador da Recherche à situação que se verifica no encontro da aranha e sua teia. Amálgama decerto esclarecedor: um narradoraranha diante de sua obra-teia, a Recherche, até certo ponto indiscerníveis.

Deslocando a reflexão de Deleuze para o debate que nos concerne no momento, diremos que a idéia de um corpo-teia-aranha é agenciadora de sintonias particularmente produtivas com a perspectiva de conexões e relações de força que defendemos para os estudos sobre produção de subjetividade e sobre as práticas linguageiras. Senão, vejamos:

- tornam-se praticamente indistintos o sujeito e seu entorno - a aranha e sua teia: a teia não é senão uma "transmutação" da aranha, isto é, resultado do trabalho realizado por glândulas localizadas no abdômen do animal responsáveis por secretar um líquido (uma proteína) que endurece em contato com o ar;

- verificam-se agenciamentos inéditos, inaugurando algo de qualitativamente diferenciado: a aranha produz um fio de extrema resistência e elasticidade, e ainda com alto grau de especialização (fios para formar a "moldura", os raios e as espirais da teia; fios destinados ao encapsulamento da presa, ou ainda para formar os casulos);

- atualiza-se uma dada sensibilidade que não se explica senão pelo agenciamento aranha-teia-presa: a aranha é capaz de sentir a aproximação de um outro corpo, de localizá-lo muito precisamente e saber o tamanho e o tipo de presa pela simples vibração produzida na teia;

- produz-se uma rede de agenciamentos imprevisíveis, os quais ultrapassam as fronteiras entre as diferentes espécies ${ }^{18}$.

18 Esse parece ser o caso dos agenciamentos operados com o homem: na Antigüidade, uso dos fios da teia de aranha nas lunetas astronômicas e em outros instrumentos ópticos; junto a tribos de índios paraguaios, a teia como poderoso anti-hemorrágico em feridas externas; pescadores da Polinésia e o fio da aranha Nephila, exímia tecedeira, como linha de pescar; nas Ilhas Hébridas, fios da teia usados como matéria-prima para a confecção de tecidos de boa qualidade e de bela cor amarelo-dourada. 
O que percebemos é que tal diversidade de agenciamentos vem justamente ratificar que, para além da dimensão do visível que trabalha para nos fazer acreditar na existência (absoluta) de formas identitárias tão permanentes quanto possível, reencontramos aqui o plano do múltiplo, das dobras e dos acontecimentos: território que transborda, ultrapassando quaisquer fronteiras!

\section{Conclusões: Alteridades em Diálogo}

O debate acerca da produção de subjetividade em $O$ bomem que copiava vem colocar em cena como elemento constitutivo a questão da alteridade:

... a subjetividade não poderia ser definida senão pela presença de uma segunda subjetividade: ela constitui um "território" somente a partir dos demais territórios que ela encontra; formação evolutiva, ela se modela em função da diferença que a constitui ela mesma em princípio de alteridade (...) Ela não existe senão no modo do acoplamento: associação com "grupos humanos, máquinas sócio-econômicas, máquinas informacionais". (Bourriaud, 2004, p. 81)

O que deve ser observado aqui é o sentido de "alteridade" que se pretende resgatar: não a alteridade que se reconhece desde sempre como remetendo a um outro (um "de fora"), mas aquilo que nos força a nos tornarmos outro:

... o momento de tornar-se outro não é senão o desposamento de Outrem enquanto mundo possível. Não existe outro senão na medida em que ele constitui o ensejo de um eu tornar-se outro. Se estou triste e alguém me sorri, o que posso desejar, nesse instante, senão um mundo possível de alegria? Da mesma forma, é exatamente o mundo de alegria que faz passar o mundo de tristeza. Só há diferenciação de meu mundo devido a outrem.

Fique claro então que alteridade não é propriamente aquilo que constitui o outro, sua qualidade, mas sim a relação do eu com aquilo que o altera. (Lambert da Silva, 2001, s/p.)

Com efeito, a individualidade da "forma-André" nada tem de essencial; é produto das conjugações produzidas pelos encontros com Gomide (o patrão), com Maria Inês (a colega de trabalho), com Feitosa (o participante do mundo da contravenção), com a mãe, com Sílvia, etc.; é também produzida por tudo aquilo que ganha corpo em seus sonhos e aspirações, em suas inquietações de operador de fotocopiadora, em seus projetos de ilustrador de quadrinhos, etc. Impossível fazer a lista exaustiva do conjunto de conexões que interferem na produção de seu modo singular de existência: 
o "eu-André" é tão-somente um efeito de superfície que se faz e se refaz ao sabor dos encontros e dos acasos que sobrevêm a um "André-mosaico".

Nesse sentido, acredito que não mais se coloque como procedente a questão de saber se o sujeito é ou não assujeitado, que margem de manobra lhe resta, etc. Após as reflexões que aqui reunimos, penso que a questão que se coloca deva ser outra: como se produzem as dobras que permitem a constituição de uma dada forma-sujeito? que forças atuam em sua produção?

... a subjetivação é sempre uma questão de dobramento. O bumano não é nem um ator essencialmente dotado de agência, nem um produto passivo ou um marionete de forças culturais; a agência é produzida no curso das práticas, sob toda uma variedade de restrições e relações de força mais ou menos onerosas, ... Nossa própria 'agência' é, pois, a resultante da ontologia que nós dobramos sobre nós mesmos no curso de nossa história e de nossas práticas. (Rose, 2001, p.181)

Se dizemos, portanto, que não vemos como procedente a questão de saber se o sujeito é livre ou não, isso se deve minimamente às seguintes considerações:

- é impossível fugir aos processos de dobramento e (des)/ (re)dobramento por meio dos quais nos tornamos sujeitos;

- as dobras não significam a produção de um interior em oposição a um mundo exterior; remetem, antes, a um estado do fora que "se travestiria", sempre provisoriamente, em "dentro";

- as dobras não significam impedimento para a ação do sujeito, que poderá fazer encontros de ordem bastante variada (melhor seria dizer que "o sujeito não poderá não fazer encontros variados");

- a ação dos sujeitos está implícita na noção de resistência: produzir um dentro é, necessariamente, resistir; em outras palavras, a dobra que constitui os sujeitos é a garantia mesma da liberdade de ação desses sujeitos.

Se as resistências têm de se dar dentro da própria trama social, e não a partir de algum lugar externo, é simplesmente porque não há exterioridades. (...) ... a resistência ao poder não é a antítese do poder, não é o outro do poder, mas é o outro numa relação de poder - e não de uma relą̧ão de poder ... (Veiga-Neto, 2003, p.151-152). 
Assim, entendo que seja preciso tomar o mais literalmente possível a recomendação de Guattari, numa feliz coincidência entre o que enuncia o autor e nosso projeto de leitura de $O$ bomem que copiava: "Se tudo já está inscrito por antecedência, mais vale morrer imediatamente! Inútil assistir ao final do filme, a gente já o conbece!" (Guattari, 1985b, p.80). Ou, numa tradução mais livre: viver para que se tudo já está dado de antemão? se já sabemos como tudo vai acabar, para que esperar of final do filme? ${ }^{19}$

Bem, O homem que copiava não nos permite quaisquer antevisões de enredo! O que é muito bom: definindo-se à proporção que a história avança, rearrumando de modo insuspeitado as diferentes peças de um quebracabeça e atualizando composições de força sempre inesperadas, o filme é, nesse sentido, promotor de vida!

Recebido em junho de 2006 Aprovado em novembro de 2006

E-mail: rochadm@uol.com.br

\section{REFERÊNCIAS BibLIOGRÁfICAS}

Bourriaud, Nicolas. 1994. Le paradigme esthétique. Chimères 21. Montreuil: Association Chimères.

BraIT, Beth (Org.). 2001. Estudos enunciativos no Brasil - histórias e perspectivas. Campinas, SP: Pontes: São Paulo: Fapesp.

Charaudeau, Patrick; Dominique Maingueneau (Orgs.). 2004. Dicionário de Análise do Discurso. São Paulo: Contexto.

Elkaїm, Mony; Isabelle Stengers. 1994. Du mariage des hétérogènes. Chimères 21. Montreuil: Association Chimères.

Deleuze, Gilles.1987. Proust e os signos. Rio de Janeiro: Forense. 1991. Foucault. São Paulo: Brasiliense.

; Guattari, Félix. s/d. O anti-édipo - capitalismo e esquizofrenia. Lisboa: Assírio \& Alvim.

Foucault, Michel.1986. Microfísica do poder. Rio de Janeiro: Graal.

19 Tendo em vista a expressividade da formulação do autor, transcrevo aqui o texto original: "Si tout est inscrit d'avance, autant crever tout de suite! Inutile de voir la fin du film, on la connaît déjà!" (Guattari, 1985b, p. 80). 
FuRTADO, Jorge. O homem que copiava (roteiro de filme). Disponível em http://www.casacinepoa.com.br. Acesso em: 29 julho 2005.

Gregolin, Maria do Rosário. 2004. Foucault e Pêcheux na Análise do Discurso - diálogos e duelos. São Paulo: ClaraLuz.

Guattari, Félix. 1985(a). Revolução molecular. São Paulo: Brasiliense. 1985(b). Entretien. Em Oury, Jean; Félix Guattari; François

Tosquelles. 1985. Pratique de l'institutionnel et politique. Vigneux: Matrice. 1990. As três ecologias. Campinas, SP: Papirus.

1992. Caosmose. Rio de Janeiro:Ed. 34.

1994. Ecologie et mouvement ouvrier. Chimères 21. Montreuil: Association Chimères.

Hall, Stuart. 2000. A identidade cultural na pós-modernidade. Rio de Janeiro: DP\&A.

Lambert Da Silva, Cléber Daniel. 2001. Devir-outro e os regimes de alteroidentidade. Disponível em < www.faac.unesp.br/pesquisa/tolerancia/ gedh/texto_direitos_cleber.htm >. Acesso em: 28 maio 2006.

MAchado, Leila D.; Maria Cristina Campello Lavrador. 2000. Configurações contemporâneas do público e do privado. Em Silva, Alacir de A. \& Barros, Maria Elizabeth B. de. 2000. Psicopedagogia - alguns hibridismos possiveis. Vitória: Saberes Instituto de Ensino.

Maingueneau, Dominique. 1989. Novas tendências em Análise do Discurso. Campinas, SP: Pontes.

2006. Cenografia epistolar e debate público. In: Possenti, Sírio; Cecília de Souza-e-Silva (Orgs.). Cenas da enunciação. Curitiba: Criar.

Martins, Carlos José. 2002. Utopias e heterotopias na obra de Michel Foucault: pensar diferentemente o tempo. In: Rago, Margareth; Luiz Orlandi; Alfredo Veiga-Neto (Orgs.). Imagens de Foucault e Deleuze - ressonâncias nietzschianas. Rio de Janeiro: DP\&A.

Naffah Neto, Alfredo. 1985. O inconsciente - um estudo crítico. São Paulo: Ática.

1991. O inconsciente como potência subversiva. São Paulo: Escuta.

O HoMem que Copiava (filme). Sinopse, texto final. Disponível em http:// www.casacinepoa.com.br. Acesso em: 29 julho 2005.

O Homem que Copiava. Roteiro e direção de Jorge Furtado. Produção de Nora Goulart e Luciana Tomasi. Manaus: Videolar, 2003. Videocassete (130 minutos): VHS, NTSC, son., color. Legendado Port., Ing., Esp., Fran. 
Orlandi, Eni P. 2001. Discurso e texto: formulação e circulação dos sentidos. Campinas, SP: Pontes.

Possenti, Sírio. 2002. Os limites do discurso. Curitiba: Criar.

Rocha, Décio. 2005. Agenciamentos coletivos de enunciação e discursos midiáticos. Semiosfera, 8, ano 5, Rev. de Pós-graduação Eco-UFRJ, disponível em www.eco.ufrj.br/semiosfera.

mimeo. Agenciamentos coletivos de enunciação em $O$ bomem que copiava. Artigo submetido ao Conselho editorial da revista Psicologia em Estudo, Universidade Estadual de Maringá.

; Bruno Deusdará. 2006. Análise de Conteúdo e Análise do Discurso: o lingüístico e seu entorno. D.E.L.T.A., LAEL, PUC-SP. São Paulo: EDUC.

Rose, Nikolas. 2001. Inventando nossos eus. Em T. T. da Silva (Org.), Nunca fomos bumanos - nos rastros do sujeito (pp. 137-204). Belo Horizonte: Autêntica.

Veiga-Neto, Alfredo. 2003. Foucault E a Educação. Belo Horizonte: Autêntica. 